\title{
Changes in Mental Health of Chinese Army during 1990-2016هA cross-temporal meta-analysis
}

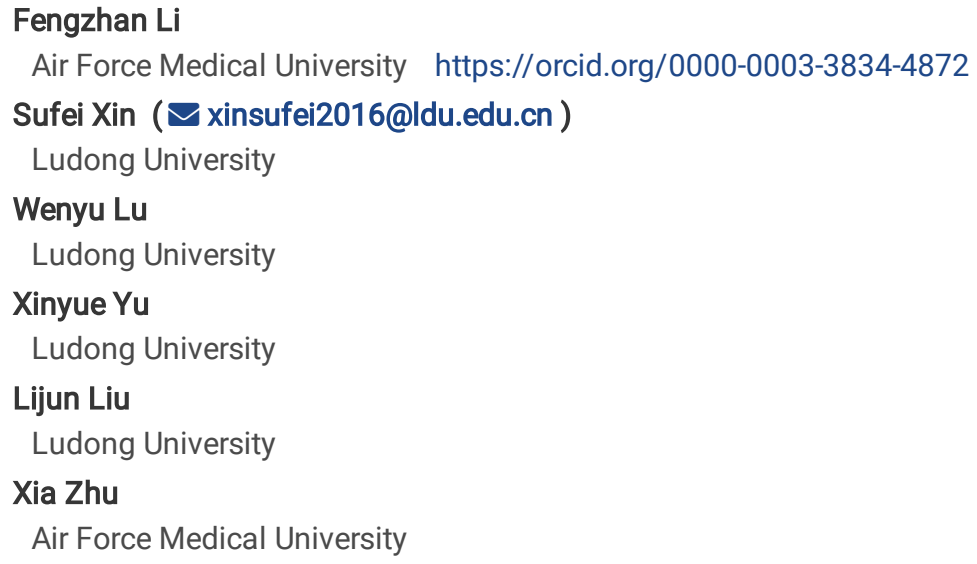




\section{Abstract}

Background: China has undergone tremendous social changes, which creates a moderately prosperous society. With the reforms of economic and national defense, Chinese armies' mental health status might also have changed over the past decades.

Methods: The present study examined the changes in mean scores on Symptom Checklist 90 (SCL-90) of 358 studies ( $N=275,123)$ from 1990 to 2016 by the cross-temporal meta-analysis.

Results: It was found that mental health status of Chinese army has been getting better since the 1990s. Meanwhile, there were significant negative correlations between mental health scores and social indicators (consumption level of residents, military budget, subsidies for military families).

Conclusions: This changing trend may be related to the level of social economic development. It indicates that Chinese national defense and military reform are heading in the right direction as well.

\section{Background}

In modern warfare, the mental health of Chinese army has become a key point in the determination of victory (Feng \& Zu, 2015). It is an initial part of military quality and reflects combat effectiveness. In April 2018, the Central Military Commission of the People's Republic of China issued the latest "Interior Service Regulations of the Chinese People's Liberations Army". In Sect. 2 (military health protection) of Chap. 13 (daily management) the document outlined how the army should carry out mental health services and enhance mental quality actively. This change indicates that the military's emphasis on mental health of the army has reached a strategic level.

In China, scholars have been begun studying the mental health of the army since the 1990s. In the 21st century, a growing number of researchers threw themselves into this field. It becomes a hot topic of military psychology in recent years (e.g., Wang, Feng, Jiang, Xia, \& Wang, 2017; Xia, Jiang, Wang, \& Wang, 2017). However, findings of previous research on the mental health status of Chinese army have been mixed. Many studies indicated that the mental health status of Chinese army is lower than domestic norms on the whole, and the incidence of mental problems is higher than that of the general population (e.g., Chen, Li, Wang, Chen, \& Wang, 2013; Zhuang, 2007). Nevertheless, other researchers argued that the overall mental health status of Chinese army is better. For instance, a few studies investigated the recruits and found that although they showed certain psychosomatic symptoms, their overall health status was good (e.g., Li, Yan, Xu, Liu, \& Cheng, 2004; Yang, Wang, Liu, Wei, Dai, \& Hu, 2015; Zhao \& Wang, 2014).

Under the circumstances, meta-analysis can be well answered in general. As a research method of systematic review on existing studies, metaanalysis was formally presented by Glass (1976). It provides a more general conclusion by calculating the effect size, which shows a comprehensive statistical analysis of many single research results. According to this method, Feng and Dai (2008) collected 77 studies and conducted a meta-analysis, which showed that the mental health of Chinese army was not bad. However, the results are static. It cannot, for example, examine whether the mental health status of Chinese army has changed over the years.

Nowadays, with 40 years of reform and opening-up, China has undergone tremendous social changes and its economic level has been greatly improved, it is about to enter a moderately prosperous society. Under such conditions, people's sense of gain and happiness continue to increase, and the mental health status of certain groups has also significantly improved, such as college students (Xin, Zhang, \& He, 2012), and migrant workers (Huang et al., 2015). It is believed that the government's concern on mental problems and the quality of higher education are the possible reasons for the improvement of college students' mental health (Xin, Zhang, \& He, 2012). In addition, the improvement of migrant workers' mental health status reflects the protection of economic and social security policy (Huang et al., 2015). But there are also some exceptions, such as teenagers ( $\mathrm{Xin}, \mathrm{Niu}, \& \mathrm{Chi}, 2011$ ) and teachers ( $\mathrm{Yi}, \mathrm{Zhao}, \mathrm{Hu}, \& \mathrm{Li}, 2014$ ), have found their mental health status decline. The researchers analyzed that Chinese adolescents' mental health status has been on a descending trajectory may related to the fierce competition of examinations and employments, which may cause adolescents more pressure and feelings of uncertainty about their future as well as lower social connectedness (Xin, Niu, \& Chi, 2011). This view is not solely existing. Twenge (2000) suggested that American adolescents' increase in anxiety between 1952 and 1993 could be attributed to decreases in social connectedness and increases in environmental dangers. The potential reason for the decline of teachers' mental health status could be their hard survival and working environment due to the social environment changes. The society, schools and the public have put forward new requirements for teachers. Therefore, they are facing various difficulties and challenges during the accomplishment (Yi, Zhao, Hu, \& Li, 2014).

As a macro-system, social environment may have direct or indirect effect on individuals' psychological development undoubtedly (e.g., Twenge, 2000; Xin \& Zhang, 2009), the above research results and discussions are the embodiment of this view. The social environment changes have a positive impact on college students and migrant workers. However, Teenagers and teachers are facing higher requirements and more challenges. Therefore, mental health status changes in polar directions. In recent decades, social environment has been changing 
for the Chinese army, military treatment and social status have been improving. For example, military budget and subsidies for military families have been increasing. According to the military demand-resource (MDR) mode (Bates et al., 2010), internal and external resources are initial roles for developing, sustaining, and restoring psychological resources. Internal resources include awareness, beliefs and appraisals, coping, decision making, and engagement. External resources are referring to environmental resources which can support individual's ability to thrive, for instance, leadership, unit, family, training, policy, and research serve (Bates et al., 2010). In fact, military budget and subsidies for military families reflect the "unit" and "policy" which belong to external resources. So is the mental health status of Chinese army getting better under such social environment?

Firmly, if we only use the traditional meta-analysis to explore this question, we cannot answer it, that is, we will ignore the possible changes of mental health status with years and social changes. Therefore, the cross-temporal meta-analysis may be the best way to answer this question. Different from the traditional meta-analysis, the cross-temporal meta-analysis can examine the change in mean scores on psychological measures with years instead of just calculating an effect size (e.g., Twenge, 2000, 2001). By recording the year of scale administration on a series of equivalent samples, the cross-temporal meta-analysis makes it possible to explore changes of psychological scores over time (e.g., Twenge, 1997a, 1997b, 2000, 2001). For instance, there were many empirical studies measured the mental health status of Chinese army (e.g., Liu, 2002; Yi, Wu, Wang, Chen, \& Wang, 2009; Xiao, Dong, Cai, Yang, Yan, \& Li, 2016) by means of a scale called Symptom Checklist 90 (Derogatis, Lipman, \& Covi, 1973), and they were published in different years. As a consequence, the changes of Chinese armies' mental health status with years will be explored by analyzing these previous studies using the cross-temporal meta-analysis technique. More importantly, the cross-temporal meta-analysis can explore the relation between Chinese armies' mental health status with social environment changes.

In sum, the present study aimed to investigate the changes in the mental health status of Chinese army over the past 27 years by means of conducting a cross-temporal meta-analysis. And explore the predictive effect of social environment changes on mental health status of Chinese army in the past decades by examining the correlations between mental health scores and social indicators over time.

\section{Methods}

\section{Literature search and inclusion rules}

The Symptom Checklist 90 (SCL-90) is a tool to evaluate psychological problems and identify symptoms with a five-point (1 to 5) rating scale for 90 items. It is worth mentioning that for scales which scoring from 0 to 4 , we add 1 to each score so that the scale scoring becoming from 1 to 5 . The checklist yields nine scores (by averaging all item scores belonging to a dimension) respectively for nine primary symptom dimensions, such as somatization, obsessive-compulsive behavior, interpersonal sensitivity, depression, anxiety, hostility, phobic anxiety, paranoid ideation, and psychoticism, with a higher score indicating a lower level of mental health (e.g., Derogatis et al., 1973; Derogatis \& Melisaratos, 1983). Chinese version of this scale has been widely used to measure mental health status of Chinese army and has demonstrated adequate reliability and validity (e.g., Liu, 2002; Yi et al., 2009; Xiao et al., 2016).

We collected the original studies reporting Chinese armies' scores on SCL-90 for the cross-temporal meta-analysis. These studies were mainly selected from the three most important Chinese academic literature databases: Wanfang, CNKI, and Chongqing VIP. Most of Chinese social science journals and a large number of the doctoral dissertations and master's theses can be found in these databases. To ensure the crosstemporal meta-analysis can be conducted, the included studies had to meet four criteria: (1) participants were armies involved in various departments; (2) armies all came from mainland China; (3) the study reported the mean and sample size; (4) the study included at least 30 soldiers (Xin, Zhang, \& Liu, 2010; Xin \& Zhang, 2009). As a result, we got 358 studies involving 275,123 soldiers from 1990 to 2016 (the year of data collection).

\section{The coding of main variables and control variables}

The mean scores of nine primary symptom dimensions, sample size, and publication year were recorded for each original study. The year of data collection was coded as two years prior to publication unless another year was mentioned in the article (e.g., Oliver \& Hyde, 1993; Twenge \& Campbell, 2001).

Besides, similar to previous literature (e.g., Liu \& Xin, 2015; Xin \& Xin, 2016), in the present study, the regions of the included studies were coded into East, Northeast, Middle, West, and Mixed (participants of the study came from two or more regions) because of Chinese economic level varies in different regions. The publication class was coded into first class, second class, and third class due to that samples in each study may differ in publication class. The first class are journals covered by Chinese Social Sciences Citation Index and Chinese Science Citation Database, the second class refers to other journals, the third class includes doctoral dissertations and master's theses. It is worth mentioning that publication class was also used to control the influence of publication bias, which refers to the problem that the studies with statistically significant results would be accepted for publication easier than those with non-significant findings (following Xin et al., 2010; Xin \& Xin, 2016). 
Considering that social economic environment is bound to have an impact on people's mental health status (Chaturvedi, 2016), Chinese national defense and military reform has been actively promoted since the reform and opening up, and the government's support and help for military life has been increasing. We choose the consumption level of residents, military budget and subsidies for military families as social indicators. According to the MDR mode, the consumption level of residents present as the "family", military budget and subsidies for military families show the "unit" and "policy". This three external resources represent social environment. In other words, this three social indicators reflect the development of Chinese economic and military reform in details. The military budget and subsidies for military families come from the China Civil Affairs Statistical Yearbook (Department of Finance and Administration Ministry of Civil Affairs of China, 2017), and the consumption level of residents obtained from the China Statistical Yearbook (National Bureau of Statistics of China, 2017).

\section{Data analysis strategy}

In the present study, the cross-temporal meta-analysis was used. In contrast to the traditional meta-analysis, it compares participants from a certain year (e.g., Twenge, 2000; Twenge \& Campbell, 2001). For each original study, the average score of target trait (e.g., anxiety, depression), publication year and sample size were recorded for cross-temporal meta-analysis. Therefore, the changing rules about Chinese armies' mental health status can be obtained by statistical analysis.

A regression equation was used and the average standard deviation $(S D)$ of the individual samples was computed in order to estimate the variable quantity of changes in mental health scores with years. The mean scores of mental health for specific years were computed (e.g., 1990 or 2015) by the regression equation: $y=B x+C$, where $x=$ the year, $y=$ the predicted mean score of mental health, $B=$ the unstandardized regression slope coefficient, and $C=$ the intercept or constant. This formula yielded the expected average mental health scores for particular years. Consistent with previous research (e.g., Twenge \& Im, 2007), the average $S D$ was obtained by averaging all the standard deviations reported in the researches.

Then, the effects of historical changes on Chinese armies' mental health status were explored. Consumption level of residents, military budget and subsidies for military families were considered as some important indicators of the macro social environment. These social indicators scores of each year (independent variable) were matched with mental health mean scores (dependent variable) of studies in corresponding year, the correlations between them could be calculated. All analyses and data management were performed in SPSS 22.0.

\section{Results}

\section{Correlations between mean scores of mental health and the year}

There was significant correlation between the mean score of each dimension and the year of data collection, $r$ ranged from -0.25 to $-0.41, p$ values $<0.01$ (see Table 1). We got nine scatter plots, which rely on the X-coordinate represented the year of data collection and the $Y$ coordinate represented the mean score of each dimension. The figures presents that all scores decreased with the year of data collection in general (take "somatization" and "obsessive-compulsive behavior" as examples, see Fig. 1and Fig. 2), although there were some fluctuations. 
Table 1

Correlations between the mean scores of SCL-90 and the year of data collection

\begin{tabular}{|c|c|c|c|}
\hline \multirow[t]{2}{*}{ Dimensions } & \multirow{2}{*}{$\begin{array}{l}\text { Without weight } \\
\text { r }\end{array}$} & \multicolumn{2}{|c|}{ With weight } \\
\hline & & $\beta_{1}$ & $\beta_{2}$ \\
\hline Somatization & $-0.25^{\star *}$ & $-0.22^{\star \star \star}$ & $-0.22^{\star \star \star}$ \\
\hline Obsessive-compulsive behavior & $-0.33^{\star *}$ & $-0.34^{\star \star \star}$ & $-0.29^{\star \star \star}$ \\
\hline Interpersonal sensitivity & $-0.41^{\star \star}$ & $-0.40^{\star \star \star}$ & $-0.39^{\star \star \star}$ \\
\hline Depression & $-0.34^{\star \star}$ & $-0.29^{\star \star \star}$ & $-0.27^{\star \star \star}$ \\
\hline Anxiety & $-0.28^{\star \star}$ & $-0.21^{\star \star \star}$ & $-0.20^{\star \star \star}$ \\
\hline Hostility & $-0.34^{\star \star}$ & $-0.28^{\star \star \star}$ & $-0.27^{\star \star \star}$ \\
\hline Phobic anxiety & $-0.24^{\star \star}$ & $-0.21^{\star \star \star}$ & $-0.22^{\star \star \star}$ \\
\hline Paranoid ideation & $-0.37^{\star \star}$ & $-0.32^{\star \star \star}$ & $-0.31^{\star \star \star}$ \\
\hline Psychoticism & $-0.36^{\star \star}$ & $-0.31^{\star \star \star}$ & $-0.31^{* \star *}$ \\
\hline
\end{tabular}

Furthermore, we conducted the regression with the mean score of each dimension (dependent variable) and the year of data collection (independent variables). Samples in each study potentially may differ publication class and in region. Therefore, these variables were used as control factors in the analyses. The result indicated that there was still a significant correlation existed between the year and mental health scores (ps<0.001, see Table 1).

\section{The decrements with years in mental health of Chinese army}

The above results showed that Chinese armies' mental health scores decreased, but we can barely know the decreased number from these results. To find the magnitude of changes for each dimension, we used regression equations to predict the mean scores of the first and last year of included studies (e.g., Twenge \& Im, 2007; Xin \& Zhang, 2009). With controls, it was found that, from 1990 to 2016 , there were different decrements for the nine dimensions listed in Table 2; $M D\left(M_{2016}-M_{1990}\right)$ ranged from -0.16 to -0.43 ; effect size $d$ ranged from - 0.38 to -0.81 . According to Cohen (1977), $d \geq 0.80$ is classified as lager effect size, $0.50 \leq \mathrm{d} \otimes 0.80$ is moderate, and $0.20 \leq \mathrm{d} \otimes 0.50$ is small. Thus, this study classified obsessive-compulsive behavior and interpersonal sensitivity as large effect size, depression, hostility, paranoid ideation and psychoticism as moderate, and somatization, anxiety and phobic as the small size. 
Table 2

Changes of Chinese armies' SCL-90 score and the variance explained by year

\begin{tabular}{|lccccc|}
\hline Dimensions & $\mathbf{M}_{1990}$ & $\mathbf{M}_{2016}$ & $\mathrm{MD}$ & $\mathrm{SD}$ & $\mathbf{d}$ \\
\hline Somatization & 1.68 & 1.47 & -0.22 & 0.51 & -0.43 \\
\hline Obsessive-compulsive behavior & 2.41 & 2.00 & -0.43 & 0.53 & -0.81 \\
\hline Interpersonal sensitivity & 1.08 & 0.66 & -0.43 & 0.53 & -0.81 \\
\hline Depression & 2.29 & 2.00 & -0.30 & 0.52 & -0.58 \\
\hline Anxiety & 0.68 & 0.47 & -0.22 & 0.48 & -0.46 \\
\hline Hostility & 2.24 & 1.98 & -0.27 & 0.54 & -0.50 \\
\hline Phobic anxiety & 1.89 & 1.74 & -0.16 & 0.42 & -0.38 \\
\hline Paranoid ideation & 0.90 & 0.56 & -0.35 & 0.52 & -0.67 \\
\hline Psychoticism & 1.08 & 0.82 & -0.27 & 0.45 & -0.60 \\
\hline MD = $\mathrm{M}_{2016}-\mathrm{M}_{1990}, \mathrm{~d}=\left(\mathrm{M}_{2016} \mathrm{M}_{1990}\right) / \mathrm{SD}, \mathrm{SD}$ is the average & standard deviation of the individual samples. \\
\hline
\end{tabular}

Hence, since the early 1990s, the scores of Chinese armies' mental health showed a significant decline, it kept dropping during $1990-2016$.

\section{Correlations between Chinese armies' mental health and social indicators}

It is clear that Chinese armies' mental health has getting better over time. Why has this phenomenon occurred? What social changes were correlated with this phenomenon? Correlating mental health scores directly with social indicators may provide a view of possible interpretation. We conducted correlation analysis between mental health scores and social indicators (consumption level of residents, military budget, subsidies for military families) which represented the macro social changes. Social indicators were matched with the mental health scores in three ways: 5 years prior to the data were collected, 3 years prior and during the year of data collection. The results presented that there were significant negative correlation coefficients between each dimension and social indicators of all ways (see Table 3 ). 
Table 3

Correlations between social indicators and Chinese armies' SCL-90 score, weighted by sample size, 1990-2016.

\begin{tabular}{|c|c|c|c|c|c|c|c|c|c|}
\hline $\begin{array}{l}\text { Social } \\
\text { indicators }\end{array}$ & Somatization & $\begin{array}{l}\text { Obsessive- } \\
\text { compulsive } \\
\text { behavior }\end{array}$ & $\begin{array}{l}\text { Interpersonal } \\
\text { sensitivity }\end{array}$ & Depression & Anxiety & Hostility & $\begin{array}{l}\text { Phobic } \\
\text { anxiety }\end{array}$ & $\begin{array}{l}\text { Paranoid } \\
\text { ideation }\end{array}$ & Psychoticism \\
\hline \multicolumn{10}{|l|}{ Actual year } \\
\hline $\begin{array}{l}\text { consumption } \\
\text { level of } \\
\text { residents }\end{array}$ & $-0.23^{\star \star}$ & $-0.33^{\star \star}$ & $-0.40^{\star *}$ & $-0.33^{\star \star}$ & $-0.28^{\star \star}$ & $-0.35^{\star \star}$ & $-0.25^{\star \star}$ & $-0.37^{\star *}$ & $-0.36^{\star \star}$ \\
\hline $\begin{array}{l}\text { military } \\
\text { budget }\end{array}$ & $-0.24^{\star \star}$ & $-0.34^{* *}$ & $-0.41^{\star *}$ & $-0.33^{* \star}$ & $-0.29^{\star \star}$ & $-0.35^{\star \star}$ & $-0.25^{\star \star}$ & $-0.38^{\star \star}$ & $-0.36^{* *}$ \\
\hline $\begin{array}{l}\text { subsidies for } \\
\text { military } \\
\text { families }\end{array}$ & $-0.16^{\star \star}$ & $-0.24^{\star \star}$ & $-0.33^{\star \star}$ & $-0.27^{\star \star}$ & $-0.22^{\star \star}$ & $-0.30^{\star \star}$ & $-0.19^{\star \star}$ & $0.31^{\star \star}$ & $-0.29^{\star \star}$ \\
\hline \multicolumn{10}{|l|}{$\begin{array}{l}\text { Three years } \\
\text { prior }\end{array}$} \\
\hline $\begin{array}{l}\text { consumption } \\
\text { level of } \\
\text { residents }\end{array}$ & $-0.22^{\star *}$ & $-0.37^{\star \star}$ & $-0.40^{\star *}$ & $-0.32^{* \star}$ & $-0.28^{\star \star}$ & $-0.34^{* *}$ & $-0.24^{\star \star}$ & $-0.37^{\star \star}$ & $-0.35^{\star *}$ \\
\hline $\begin{array}{l}\text { military } \\
\text { budget }\end{array}$ & $-0.23^{* *}$ & $-0.32^{* *}$ & $-0.40^{\star *}$ & $-0.32^{* *}$ & $-0.28^{\star \star}$ & $-0.34^{* *}$ & $-0.24^{\star \star}$ & $-0.37^{\star \star}$ & $-0.36^{* *}$ \\
\hline $\begin{array}{l}\text { subsidies for } \\
\text { military } \\
\text { families }\end{array}$ & $-0.10^{\star}$ & $-0.18^{\star \star}$ & $-0.23^{\star *}$ & $-0.18^{* \star}$ & $-0.17^{\star \star}$ & $-0.20^{\star *}$ & $-0.15^{\star \star}$ & $-0.21^{\star \star}$ & $-0.20^{* *}$ \\
\hline \multicolumn{10}{|l|}{$\begin{array}{l}\text { Five years } \\
\text { prior }\end{array}$} \\
\hline $\begin{array}{l}\text { consumption } \\
\text { level of } \\
\text { residents }\end{array}$ & $-0.23^{* *}$ & $-0.32^{* *}$ & $-0.40^{\star *}$ & $-0.33^{\star \star}$ & $-0.28^{\star \star}$ & $-0.34^{\star \star}$ & $-0.24^{\star \star}$ & $-0.37^{\star \star}$ & $-0.36^{\star *}$ \\
\hline $\begin{array}{l}\text { military } \\
\text { budget }\end{array}$ & $-0.22^{\star \star}$ & $-0.32^{\star \star}$ & $-0.40^{* *}$ & $-0.33^{\star \star}$ & $-0.28^{\star \star}$ & $-0.34^{* *}$ & $-0.25^{\star \star}$ & $-0.37^{\star \star}$ & $-0.35^{\star \star}$ \\
\hline $\begin{array}{l}\text { subsidies for } \\
\text { military } \\
\text { families }\end{array}$ & $-0.18^{\star \star}$ & $-0.17^{\star \star}$ & $-0.19^{\star \star}$ & $-0.17^{\star \star}$ & $-0.18^{\star \star}$ & $-0.13^{\star \star}$ & $-0.13^{\star \star}$ & $-0.14^{\star \star}$ & $-0.19^{\star \star}$ \\
\hline${ }^{*} p<0.05,{ }^{* *} p<$ & $01,{ }^{* \star *} p<0.001$ & & & & & & & & \\
\hline
\end{tabular}

\section{Discussion}

The present cross-temporal analysis supported our hypothesis that Chinese armies' mental health status has been getting better since the 1990s, which resolve previous controversy to some degree. According to the military demand-resource (MDR) mode (Bates et al., 2010), the roles of internal (personal) and external (environmental) resources are particularly important for developing, sustaining, and restoring psychological resources. Internal resources include awareness, beliefs and appraisals, coping, decision making, and engagement. External resources, referring to environmental resources which can support individual's ability to thrive, comprise leadership, unit, family, training, policy, and research serve. MDR mode was used to assess mental health status for military forces based on the Total Force Fitness (TFF), which proposed by the US army in 2009. The conclusion of the present study may provide evidence for this model, and it also reminds us that it might be vital to achieve the demand of armies' external resource in order to maintain mental health status. In fact, the Chinese government might be always doing properly in this regard.

As we know, the socialist economic system with Chinese characteristics has been constantly readjusted and improved since the famous 1992 "southern tour" by Mr. Deng, in which he called for bolder reforms and encouraged people to be affluence. Nowadays, tremendous changes have taken place in the society, and people's lives have become more and more prosperous. In 2010, China became the second largest economy in the world. Meanwhile, the reform of national defense and army has been actively promoted. First of all, many efforts have been made to promote the revolutionary, modernized and regularized construction of army, which fundamentally consolidated and improved the 
combat effectiveness. For instance, since the 1990s, Chinese army forces have undergone three disarmament in 1997, 2005 and 2015. It is aimed at improving strength and efficiency of military.

Secondly, Chinese defense expenditure, including personnel expenses, costs for maintenance of activities and equipment, has been constantly increased. It provides material security for their families' development and life. According to the data, from 1989 to 1996, defense expenditure was in the lower growth period; during 1996 to 2009, it was in the compensatory growth period; after 2010, China slowed down its economic development and the national defense expenditure kept its pace with the economic growth (Xia, Sun, \& Liu, 2015).

Finally, military sense of honor have been constantly enhanced, the government were always striving to promote military honor system construction and safeguard the legitimate rights of military and their families. In October 2017, President Xi pointed out that we should make military the respected profession of the whole society in the 19th report of the Communist Party of China (CPC) (Xi, 2017), which warmed military and touched their families' heart as well as triggered strong resonance. In fact, the honor system of the People's Liberation Army has been gradually improved during the long period of revolution and construction, and the Chinese government has introduced many regulations and systems concerning military honor.

Nowadays, the national honor system defines the political, economic and social status of military in legal form, determines the rights and guarantees enjoyed by military and their families, standardizes the specifications and procedures of various ceremonial and etiquette of military, and pays great attention to the implementation and supervision of the system as well as the construction of social atmosphere. In this situation, the rights of military can be maintained, the morale of troops can be encouraged, and the military have felt the sense of honor and gained abundantly.

The above social and economic changes and national defense reform measures specific to the Chinese armies' life may be the consumption level of residents, military budget, subsidies for military families and so on. Our results showed that correlations between these social indicators and mental health scores were statistically significant, which indicating that these social changes may help to improve Chinese armies' mental health status. In addition to the macro factors mentioned above, the Chinese military has also done a lot of work at the micro level. For example, after entering the 21st century, the psychological testing system of recruitment developed by Air Force Military Medical University began to be used and it promoted throughout the military gradually (Wu, 2006). Young people who have better psychological quality can enter the army by the preliminary psychological screening work before enlistment, and they could adapt to the military life successfully. During the service period, military also conducts psychological evaluation on army regularly, and provides psychological counseling, psychological education and other effective work based on the evaluation results. The results of this study showed that Chinese armies' work may be paid off.

As regards the conclusion of previous research on Chinese armies' mental health was controversial, some researchers contended the reason could be that they choose different mental health standards and compare with various norms (Feng \& Dai, 2008). Some norm scores were lower and others were higher. Therefore, some researchers believed that the mental health status of army was stable, others insisted it was poor. However, this view was still static. We suggest the overarching reason is that researchers investigated Chinese armies' mental health status in different periods, but they did not take into account the possible impact of social backgrounds. The results of this study may back up this view. Although Chinese armies' mental health status fluctuated for a few years, the trend was going to be better in general.

\section{Conclusions}

Our findings are crucial because this study systematically reviews the literature on Chinese armies' mental health over the past 27 years using a cross-temporal meta-analysis technique and resolves previous controversy about Chinese armies' mental health status. Besides, our study support that Chinese armies' mental health status has gradually improved over years. On the one hand, it might be related to the level of social economic development. On the other hand, it may indicate that Chinese national defense and military reform are in the proper direction. The Chinese government should adhere to this road of reform with Chinese characteristics. Nevertheless, it has limitations. For example, in this study, the majority of respondents were male and there were few studies involving female soldiers, namely the present study limits its conclusions to male soldiers. In addition, to obtain causal relationship knowledge, future research should employ an experimental design to identify how the social changes improve armies' mental health. Last, publication bias can't be analyzed in the cross-temporal analysis based on its data structure. Hopefully, it may be resolved with the methodical improvement in the future.

\section{Declarations}

\section{Abbreviations}

Not applicable. 


\section{Acknowledgements}

Not applicable.

\section{Authors' contributions}

LFZ, XSF, LWY, YXY, LLJ and ZX conceived the study, LWY, YXY and LLJ retrieved the literature and analyzed the data. LFZ wrote the paper. $X S F$ and $Z X$ critically reviewed drafts of the paper. All authors approved the final version of the manuscript.

\section{Funding}

The present study was funded by the Major Project of Medicine Science and Technology of PLA (Grant No. AWS17J012). The funder played no role in the design of the study, or the collection, analysis, and interpretation of data, or in the writing of the manuscript.

\section{Availability of data and materials}

The datasets used and/or analyzed during the current study are available from the corresponding author on reasonable request.

\section{Ethics approval and consent to participate}

Not applicable. The present manuscript only involves the data of released publications.

\section{Consent for publication}

Not applicable.

\section{Competing interests}

The authors declare that they have no competing interests.

\section{References}

Bates, M. J., Bowles, S., Hammermeister, J., Stokes, C., Pinder, E., Moore, M., \& Burbelo, G. (2010). Psychological fitness. Military Medicine, 175(8), 21-38

Chaturvedi, S. K. (2016). Mental health towards social and economic inclusion: Nothing else matters! Journal of Psychosocial Rehabilitation and Mental Health, 3(1), 1-3.

Cohen, J. (1977). Statistical power analysis for the behavioral sciences. New York: Academic.

Chen, Y., Li, X., Wang, G., Chen, G., \& Wang, Y. (2013). Evaluation and analysis on mental health of 11387 recruits. People's Military Surgeon, $56(6), 624-625$.

Department of Finance and Administration Ministry of Civil Affairs of China. (2017). China Civil Affairs' Statistical Yearbook. Beijing: China Statistics Press.

Derogatis, L. R., Lipman, R. S., \& Covi, L. (1973). SCL-90: An outpatient psychiatric rating scale-preliminary report. Psychopharmacology Bulletin, 9(1), 13-28.

Derogatis, L. R., \& Melisaratos, N. (1983). The brief symptom inventory: An introductory report. Psychological Medicine, 13(3), 595-605.

Feng, Z., \& Dai, Q. (2008). A meta-analysis concerning the mental health status of members of the Chinese army. Acta Psychologica Sinica, 40(3), 358-367.

Feng, Z., \& Zu, X. (2015). Mental health assessment for military men: theories and model. Academic Journal of Third Military Medical University, 37(22), 2207-2212.

Glass, G. V. (1976). Primary, secondary and meta-analysis of research. Education Research, 6(5), 3-8.

Huang, S., Hou, J., Zhang, M., Xin, Z., Zhang, H., Sun, L., \& Dou, D. (2015). A cross-temporal meta-analysis of changes in chinese migrant workers' mental health: 1995 2011. Acta Psychologica Sinica, 47(4), 466-477. 
Li, C., Yan, J., Xu, T., Liu, X, \& Cheng, L. (2004). Analysis of mental health status and its related factors in 1077 recruits. Academic Journal of Second Military Medical University, 25(6), 584-586.

Liu, D., \& Xin, Z. Q. (2015). Birth cohort and age changes in the self-esteem of Chinese adolescents: A cross-temporal meta-analysis, 19962009. Journal of Research on Adolescence, 25(2), 366-376.

Liu, S. (2002). Psychological problem self-measurement in serviceman. Academic Journal of Second Military Medical University, 23(8), 905907

National Bureau of Statistics of China. (2017). China statistical yearbook. Beijing: China Statistic Press.

Oliver, M. B., \& Hyde, J. S. (1993). Gender differences in sexuality: A meta-analysis. Psychopharmacology Bulletin, 114(1), $29-51$.

Twenge, J. M. (1997a). Changes in masculine and feminine traits over time: A meta-analysis. Sex Roles, 36(5-6), 305-325.

Twenge, J. M. (1997b). Attitudes toward women, 1970-1995: A meta-analysis. Psychology of Women Quarterly, 21(1), 35-51.

Twenge, J. M. (2000). The age of anxiety? Birth cohort change in anxiety and neuroticism, 1952-1993. Journal of Personality and Social Psychology, 79(6), 1007-1021.

Twenge, J. M. (2001). Birth cohort changes in extraversion: A cross-temporal meta-analysis, 1966-1993. Personality and Individual Differences, $30(5), 735-748$.

Twenge, J. M., \& Campbell, W. K. (2001). Age and birth cohort differences in self-esteem: A cross-temporal meta-analysis. Personality and Social Psychology Review, 30(4), 321-344.

Twenge, J. M., \& Im, C. (2007). Changes in the need for social approval, 1958-2013. Journal of Research in Personality, 41(1), 171-189.

Wang, J., Feng, Z., Jiang, J., Xia, L., \& Wang, Y. (2017). A comparative analysis of foreign and Chinese military mental health and prospect of research. Journal of Preventive Medicine of Chinese People's Liberation Army, 35(9), 1158-1161.

Wu, S. (2006). Predictive study of Chinese recruitment psychological screen system for enlisted soldiers. Unpublished Master's Thesis, Fourth Military Medical University.

$\mathrm{Xi}, \mathrm{J}$. (2017). Win victory, build a well-off society in an all-round way and win the great victory of socialism with Chinese characteristics in the new era--Report on the nineteenth National Congress of the Communist Party of China. Beijing: People's Publishing House.

Xia, L., Jiang, J., Wang, J., \& Wang, Y. (2017). Comparative study of Chinese and foreign military mental health. China Journal of Health Psychology, 25(8), 1261-1267.

Xia, Q., Sun, Z., \& Liu, S. (2015). Read Chinese defense expenditure impartially: from compensatory growth to coordinated growth. East China Economic Management, 29(3), 85-90.

Xiao, J., Dong, W., Cai, W., Yang, Z., Yan, J., Li, J., \& Li, W. (2016). Survey on mental health condition of a panzer troop. Journal of Third Military Medical University, 38(20), 2240-2243.

Xin, Z., Niu, J., \& Chi, L. (2011). Birth cohort changes in Chinese adolescents' mental health. International Journal of Psychology, 47(4), 287295.

Xin, S. F., \& Xin, Z. Q. (2016). Birth cohort changes in Chinese college students' loneliness and social support: One up, as another down. International Journal of Behavioral Development, 40(5), 398-407.

Xin, Z., Zhang, L., \& Liu, D. (2010). Birth cohort changes of Chinese adolescents' anxiety: A cross-temporal meta-analysis, $1992-2005$. Personality and Individual Differences, 48(2), 208-212.

Xin, Z., \& Zhang, M. (2009). Changes in Chinese middle school students' mental health (1992-2005): A cross-temporal meta-analysis. Acta Psychologica Sinica, 41(1), 69-78.

Xin, Z., Zhang, M., \& He, L. (2012). Changes in college students' mental health: A cross-temporal meta-analysis. Acta Psychologica Sinica, 44(5), 664-679. 
Yang, Z., Wang, C., Liu, B., Wei, H., Dai, J., \& Hu, W. (2015). Mental health examination of 3017 recruits and establishment of a comprehensive assessment model for recruits' mental health. China Journal of Health Psychology, 23(10), 1471-1474.

Yi, L., Wu, G., Wang, J., Chen, S., \& Wang, Z. (2009). Analysis on mental health and its associate factors in rescue troops after earthquake. Advances in Psychological Science, 17(3), 567-569

Yi, X., Zhao, Q., Hu, W., \& Li, J. (2014). Changes in mental health of Chinese teachers (1994-2011): A cross-temporal meta-analysis. Journal of Beijing Normal University (Social Sciences), 243(3), 12-22.

Zhao, B., Wang, H., Gao, Z., Yu, H., Guo, W., Bi, Y., \& Wang, G. (2014). Mental health situation in recruits enlisted in 2013 in a certain troop and related factors. China Journal of Health Psychology, 22(4), 560-562.

Zhuang, J. (2007). Mental health status and its adjustment of young soldiers in the new era. Journal of Military Surgeon in Southwest China, 9(2), 91-93.

\section{Figures}

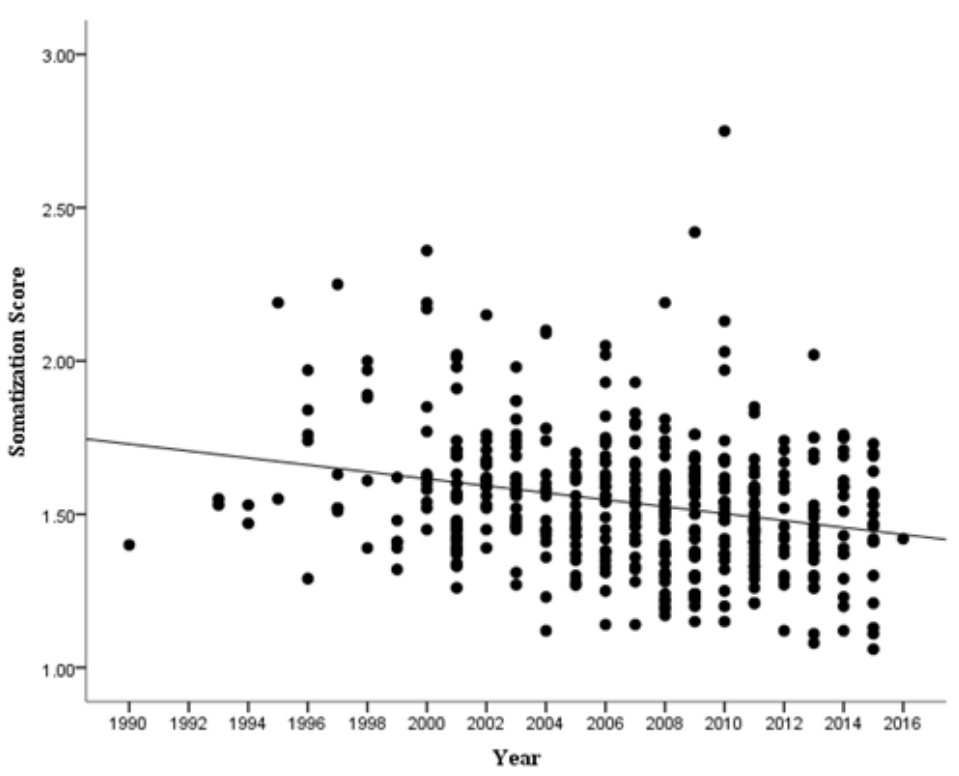

Figure 1

Changes in Chinese armies' somatization, 1990-2016. 


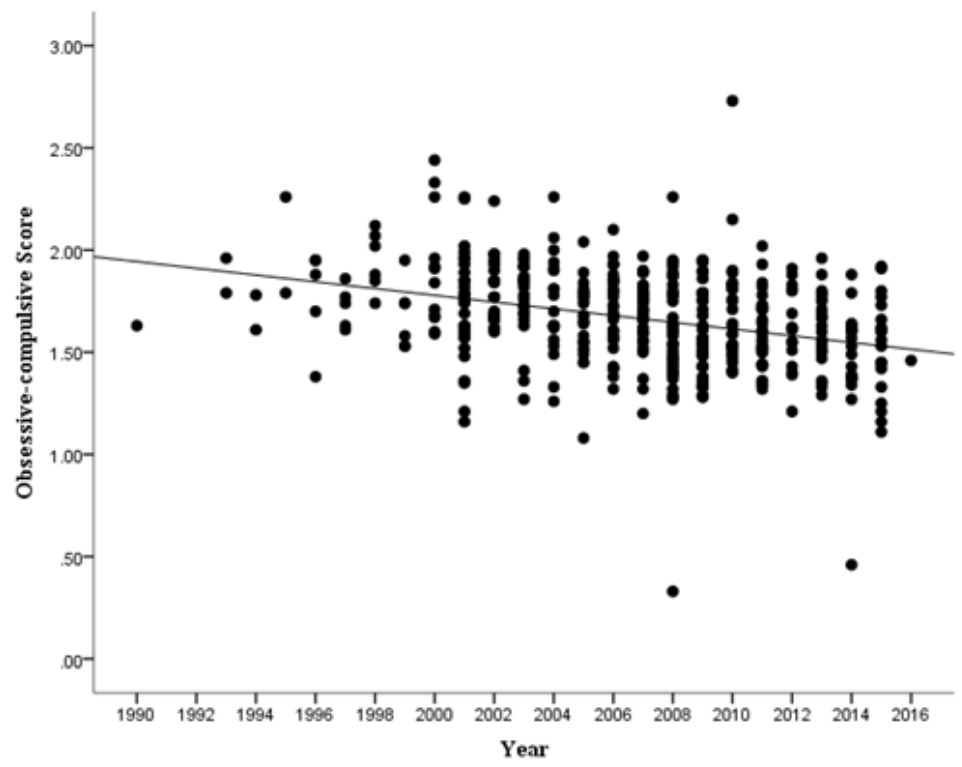

Figure 2

Changes in Chinese armies' obsessive-compulsive, 1990-2016. 